\title{
FESTIVA DESTRUCCIÓN. ENTREVISTA A CRISTINA MORALES ${ }^{*}$
}

FESTIVE DESTRUCTION. INTERVIEW WITH CRISTINA MORALES

Aina Pérez Fontdevila

Universidad de Alcalá aina.perez@uah.es

MaYte Cantero Sánchez

Universitat Autònoma de Barcelona

mayte.cantero@uab.cat

He descubierto yo otra manera de divertirse más divertida todavía, donde nos aguardan mayores placeres y poderes, porque seremos anfitrionas y no invitadas, Juana, y esa manera empieza por nuestro grito: un cartel en la puerta, de nuestro puño y letra y en romance, dirá: "Fiesta aquí hoy, mañana y siempre, siempre, siempre".

Cristina Morales - Teresa de Jesús

El 28 de octubre de 2020, en el marco del Simposio Internacional "¿Cómo ser escritora? Género y autoridad en el campo literario contemporáneo", ${ }^{1}$ conversamos con Cristina Morales acerca del sujeto "mujer" y la noción de "autora", la teoría queer, la sociedad capacitista, la misoginia en la crítica literaria o las relaciones y jerarquías entre arte y acción política. Cerrábamos el encuentro agradeciéndole a la escritora granadina que, a través de sus textos, hubiera transformado tantas veces nuestras incoherencias en humor y nos hubiera provocado tanto placer. Concretamente, "el placer de localizar el dedo índice de la mano, estirarlo y dirigirlo

\footnotetext{
" Esta entrevista se inscribe en el proyecto "Pensar lo real: autoficción y discurso crítico" (FFI201789870-P), dentro de las actividades desarrolladas por Aina Pérez Fontdevila gracias a un contrato postdoctoral Juan de la Cierva-Formación.

${ }^{1}$ El simposio fue organizado por GILCO. Grupo de Investigación en Literatura Contemporánea (Universidad de Alcalá), en colaboración con el Grupo Cuerpo y Textualidad (Universitat Autònoma de Barcelona) y el Instituto de Estética de la Pontificia Universidad Católica de Chile, con el apoyo del Instituto de la Mujer y para la Igualdad de Oportunidades.
} 
contra tu sometedor" (nosotres mismes, en tantos casos); "aprender a señalar, pasar de víctima a sujeto: ese placer" (Morales 2018b: 26). Estos y otros "placeres y poderes" aguardan a les lectores en estas páginas.

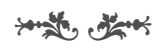

En una reseña de Lectura fácil (2018) donde se tilda la novela de "sermón anarquista" y su discurso de "ideológico" y "totalitario", el crítico termina rehusando "discutir literariamente esta novela con Cristina Morales, o con cuantos recen genuflexos su ácrata santidad" (Pozuelo Yvancos 2019). Damos comienzo a esta entrevista con palabras ajenas a las que vamos a conversar porque ello nos permite dos cosas. En primer lugar, advertir que nos sabemos ubicadas en, o en relación con, un marco o un campo (académico, literario) en el que, en efecto, siempre han sido otros los que "[administran] lo que creen que es un saber cuando es sobre todo un poder (etc. etc.)" (Pozuelo Yvancos 2019). En segundo lugar, porque nosotras tampoco queremos "discutir literariamente" con Cristina Morales, es decir, discutir desde lo que ese poder/saber determina que literariamente puede significar. Obra autónoma, más literatura cuanto menos heterotélica (ideológica, politizada, etc.), producida por una "creadora genial" que es ajena a "las condiciones materiales de la creación literaria" (Morales 2020b: 36) y cuya tarea comienza "de tapas para adentro (como la liberal concepción de la vida privada)" (2020b: 29-30). Queremos situarnos de "tapas para afuera" o, más bien, contribuir a desmantelar ese "dentro/ fuera" -del sistema literario, de la obra o de este acto-. Para ello, empezaremos citando un fragmento que no nos interpela, pero sí nos interpela; que interpela, como mínimo, ciertas prácticas académicas y culturales con las que podría parecer vinculado este simposio. En Los combatientes (2013), la narradora Cristina Morales explica brillante y satíricamente la invitación a la Feria del Libro de Granada, en 2012, para participar en una mesa redonda sobre relato escrito por mujeres:

Junto a la ilusión y los temores acogía cierto recelo por tratarse de una mesa feminizante feminizada fémina, porque a mí el feminismo no se me da bien y menos si viene de una institución pública, que se me dan todavía peor. Lo que no me podía imaginar era que la mesa se llamara "Ellas también cuentan", y entonces los recelos se convirtieron en serias dudas sobre la pertinencia de que mi nombre figurara debajo de ese rótulo. Porque "Ellas cuentan" habría sido feminista casposo pero "Ellas también cuentan" era paternalista. Es curioso lo cerca que están el machismo paternalista y el feminismo casposo. Igual de poco habría comulgado con un título combativo del tipo "Contar con el coño", pero eso por lo menos tiene la legitimidad de una consigna, de una lucha por lo que sea aunque no la comparta, y además tiene gracia. Con lo mal que se me da a mí el feminismo, a cuyo conocimiento solo accedo por el método suspectivo, y tuve que aceptar la invitación porque mi coño se sintió interpelado. (Morales 2020a: 73) 
Aina Pérez Fontdevila: Esta cita aparece en un capítulo titulado "Yo no iba a venir". Teniendo en cuenta que este simposio es, por lo menos aparentemente, un simposio "feminizante feminizado fémina", nuestra primera pregunta es obvia: ¿ibas a venir?

Cristina Morales: Recibo las invitaciones dirigidas exclusivamente a escritoras mujeres desde dos lados y, generalmente, desde ahí vengo decidiendo. A veces llegan desde espacios que serían una versión light de las reuniones no mixtas en espacios liberados, que tienen toda mi simpatía (colectivos que combaten la violencia sexual, fiestas de barrio o, sencillamente, colectivos de mujeres que quieren hablar de su sexualidad...): la de este simposio sería, para mí, una invitación light, y aun así amable, de lo no mixto como búsqueda de un espacio de confort y de seguridad. A la vertiente a la que suelo decir que no es a aquella donde el conglomerado femenino es medidor de una serie de discursos de género, igualitarios, de cuota; donde a las mujeres invitadas se las destaca por su talento y a los organizadores, por su compromiso con la igualdad. A estos espacios suelo negarme a ir salvo que me engañen, me den gato por liebre o haya mucha pasta. Si hay mucha pasta, voy y cobro la pasta.

Mayte Cantero Sánchez: Para seguir con la autocrítica, queríamos preguntarte sobre la reiteración del término "escritora" o "autora" en la actualidad. Nuestro simposio contiene en el título la palabra "género", aunque versa exclusivamente sobre autoras mujeres. Sabemos que "género" no se refiere solo a "mujeres" y que "mujeres" no equivale a "mujer cisgénero". Sabemos también que hay ejes de opresión tan importantes como la racialización o la diversidad funcional y cognitiva, que tú sacas a colación en Lectura fácil. Y, sin embargo, lo hemos vuelto a hacer. ¿Qué opinas de la estrategia de desmantelar la noción de autor (masculina, cisgénero, blanca, occidental, descorporeizada, etc.) recurriendo simplemente a la de autora, que también implica exclusiones y privilegia el eje del género, como si fuera el que más nos oprime a todes?

C.M.: Qué alegría esa autocrítica tan bien formulada. Algo similar me pasó ayer: unos cuantos de nosotros nos vimos empantanados en detenciones, comisarías y juzgados por asistir a una manifestación contra las últimas medidas represoras de los gobiernos y, con la pasta por delante, conseguimos una abogada que lo hizo todo superbién y superfácil, y salimos y celebramos. Una compañera comentaba, muy finamente, la alegría de ejercer la crítica desde la calle, desde la barricada, y luego estar lo suficientemente organizadas como para tener la pasta, pagar, salir y celebrar. Creo que en vuestra actitud hay algo similar: dar la batalla por la construcción del discurso y, al mismo tiempo, ser nosotras mismas nuestras propias "otras", nuestras propias censoras, nuestros propios policías, indica que estamos en el buen camino; el camino que se nos ha negado históricamente a las mujeres, el de la posibilidad del disenso entre nosotras (y digo "mujeres" para entendernos: es decir, al sujeto no masculino).

Lo explica muy bien María Galindo -ella que es absolutamente anarquista y antiparlamentaria- cuando afirma que jamás en ningún parlamento de nin- 
gún estado los diputados consentirían que se les agrupara y clasificara por la pertenencia a un sexo/género. Sin embargo, es habitual que en todos los estados declarados democráticos o con un gobierno parlamentario a las mujeres se las aglomere, y además de una manera muy ramplona: entendiendo que el mero hecho de ser mujer -insisto: sea lo que sea "ser mujer"- ya es un valor; y presumiendo que, en la esfera de la opinión pública, hay temas en los que las mujeres no pueden disentir entre sí. Entonces, creo que es superbuena noticia que nosotras mismas planteemos y nos permitamos discutir los términos del debate, que contradigamos los propios marcos de significado que nos estamos dando. Gracias, Mayte, por dar la oportunidad de criticar el marco de significado presente. Como ya decía, no creo que se pueda dar una respuesta definitiva: ¿estamos tirando piedras a nuestro propio tejado? Pero, ¿qué es nuestro tejado? A lo mejor mi tejado no es tu tejado. Yo puedo rentabilizar económicamente la posición de autora e incluso la puedo rentabilizar simbólicamente y hacer una tarea de guerrilla desde ella. Creo que eso es importantísimo. Cuando me di cuenta de que era posible ser muy dañina utilizando las herramientas que el poder me daba inocentemente se abrió todo un mundo para mí.

M.C.S.: Recientemente, Laura Freixas -que también participa en la antología Tsunami. Miradas feministas (Sanz 2019)- tuiteaba lo siguiente: "La sociedad nos impone un género según el sexo, si es chico azul, si es chica rosa. El feminismo quiere abolir el género, ni rosa ni azul, sino personas. El pensamiento queer quiere mantener el rosa y el azul, solo que a la carta, eso es liberalismo, no feminismo". Nos gustaría saber tu opinión sobre esta consideración de lo queer, lo no binario, lo trans, como un refuerzo y no como una crítica al liberalismo, cuando quizá es un lugar de enunciación tan potente o más que el históricamente asumido por las mujeres cisgénero. ¿Cómo te posicionas respecto a este lugar? Para ti, ¿interpela a la destrucción o interpela a la perpetuación de esta línea de pensamiento?

C.M.: Sin ser ninguna entendida, sin haber leído en profundidad más que a través de fanzines, a través de conocimiento generado colectivamente o de la experiencia con colegas en espacios liberados, se me hace muy sencillo atacar este tuit por esa idea humanista de que todos somos seres humanos. Tengo una batalla contra la noción de "persona". Ese mismo tuit sobre género lo podemos aplicar a cualquier otro eje de opresión. Sucede lo mismo en el mundo de la discapacidad: frente a la discriminación entre discapacitado y no discapacitado, "todos somos personas". Con esto se le llena la boca, por ejemplo, a Pablo Pineda. Ello refiere a un lugar absolutamente liberal, donde la noción de persona lo único que quiere hacer es acabar con las tensiones y con las relaciones de poder: voy a decir "personas" para no decir "racializados", para no decir "oprimidos".

En lo que se refiere a la teoría queer, es un lugar con poderío, iya verás si lo es! Aunque no soy capaz de articular el discurso teóricamente, colegas que lo tienen más claro me han llamado a mí misma queer y me ha generado una gran sorpresa y una gran alegría. ¡Qué imagen tan disturbadora! Pero creo que, como la sexualidad - no ya la propia sino como constructora de realidades, o sea, la 
sexualidad entendida a nivel social- , la descubro en ambientes que son -ahora lo sé- ambientes queer, para mí no ha sido necesaria una reflexión previa. Cuando por primera vez me he puesto a debatir sobre la legitimidad o no de que sexualidades disidentes se expresen por la calle y no reciban una paliza, ha sido a la hora de responder a la paliza. Es decir: me formo y escribo desde muy tempranamente desde esos lugares de enunciación.

En una charla que tuvimos en común con María Galindo en Sevilla también nos preguntaban por esto, y voy a volver a citarla: decía que era absolutamente perverso y deliberado afirmar que la teoría queer era la responsable de la división de las feministas. Obviamente, quien dice eso es la teoría feminista liberal, que se siente tocada y casi hundida en sus premisas y que, por supuesto, no puede tolerar ese otro enunciado de las mil caras que es lo queer. Yo no tengo problema con la aprehensión de las cosas que no entiendo, no me genera ansiedad. La poeta Sara Torres dice que aprender a vivir con esa no necesidad de control y de saber y de aprehensión es bueno, y yo estoy con ella.

M.C.S.: Como estamos hablando de colectivos que hablan sobre otros colectivos, la pregunta resulta obvia. Después de los dos años que han pasado desde la publicación de Lectura fácil, ¿cuál es tu posición o tu sensación respecto al hecho de haber ficcionalizado a cuatro mujeres con "discapacidad" o con "diversidad funcional"? ¿Cuál ha sido la recepción sobre esta cuestión?

C.M.: Creo que me pasa lo mismo con la palabra "colectivo" que con la palabra "persona", Mayte. Porque parece que el colectivo es todo aquello que no es la centralidad de la persona. Hasta hace dos días, incluso todavía hoy en día, las mujeres éramos un colectivo. Entonces, en el momento de la escritura esos cuatro personajes para mí no tenían un correlato en nada de la realidad que se parezca a un colectivo. Que, obviamente, en el momento de la recepción sean leídas de manera verosímil como cuatro ficciones de cuatro personas que están institucionalizadas en centros para personas con discapacidad, me salva, o sea, me ayuda a que la novela sea leída. Pero, al nivel de la escritura, las preocupaciones iban en el sentido absolutamente contrario: en descolectivizar a las colectivizadas y acercarlas lo más posible a mí, en un ejercicio de hermanamiento.

En una sociedad capacitista, la diferencia principal entre dos personas, teniendo una de ellas un grado de discapacidad reconocida, será siempre esa, obviando cualesquiera otras. Por supuesto, esa diferencia establecida capacitistamente evita cualquier tipo de hermandad también. Es más, desde lugares de izquierda donde se podría pretender cierto tipo de hermandad, esta se censura porque se entiende que cualquier cordialidad que yo quiera establecer con la discapacitada -y habría que crear un neologismo como racializada-; que cualquier intento de acercamiento mío hacia la presa por discapacidad, es una sustitución, una ocupación del discurso que ella debería enunciar por sí misma. Esto lo he sabido ahora, en el minuto de la recepción. Pero estos debates, durante la ejecución de la escritura, no estaban presentes en mí para nada. Y precisamente que no estuvieran presentes ayudaba a que siguiera escribiendo, porque no 
sentía ningún tipo de pudor a la hora de crear un personaje que tuviera tantos cromosomas. Siempre digo que no represento nada en la novela: "Esto no es una pipa". Efectivamente, esto no son cuatro personajes con discapacidad ni esto es un centro de reclusión de personas con discapacidad; esto tampoco es Pablo Pineda, aunque salga con su nombre. Parece que el lugar de la representación en la literatura y en el arte en general se asimila ahora a un lugar de representación política democrática, o sea, que solamente puedo escribir aquello que estaría legitimada a hacer políticamente en la esfera pública. Ese discurso acaba con cualquier posibilidad de proyección de una mirada nueva en el arte y en la literatura.

A.P.F.: Nos gustaría quedarnos un poco más con las protagonistas de Lectura fácil y darle espacio a la mirada de Nati. Te trasladamos la pregunta de una compañera, Patricia García: Nati tiene la capacidad de articular de forma brillante las incoherencias que subyacen en los colectivos sociales y políticos actuales, y en nuestra forma de pensar y proceder como individuos e integrantes de una sociedad. Lo mismo se ha señalado, en general, de tu escritura: su capacidad de poner al lector "contra las cuerdas", de señalar nuestras "contradicciones, ignorancia, doble moral, la rigidez de alguno de nuestros prejuicios" (Suau 2018). A mí me daría miedo abrir la boca ante Nati. ¿Qué crees que opinaría de ti ese personaje? ¿Con qué incoherencia tuya se le activarían las compuertas?

C.M.: Qué divertido este ejercicio de ficción sobre la ficción. Eso significa que la realidad del libro está ya en nuestra realidad: me doy con un canto en los dientes. Para mí Nati es una compañera politizadora. Entonces, cuando estoy muerta de miedo, pienso en ella y digo: "a ver, ¿qué haría y qué consecuencias tendría?". Las dos cosas, porque el personaje de Nati es supertrágico.

La respuesta a tu pregunta quizá está en lo que empezaba anunciando al principio de la charla: cuando hay mucha pasta de por medio una acaba diciendo que sí porque hay mucha pasta de por medio. Porque he llegado a la conclusión reciente -no estoy descubriendo la pólvora- de que ni siquiera el mejor de los salarios en el más descansado de los trabajos viene a remunerar el esfuerzo que supone trabajar. De que ahí el dinero cumple una función completamente simbólica de acallamiento y bálsamo. Creo que el trabajo responde a un estado policial de las cosas. Entonces, esta sería la reflexión que debería hacer cada vez que digo "que me pongan la cifra en el asunto del mensaje; si no, no sigo hablando". Me debería recordar a mí misma que esa cifra no paga nada. El consuelo es necesario, imprescindible, pero el trabajo y el esfuerzo no están pagados. Eso diría Nati.

M.C.S.: Te trasladamos otra pregunta de la misma compañera: Lectura fácil parece estar escrito $y$, así se lee frecuentemente, contra el capitalismo sanitario, la hipernormalización, el activismo "alternativo", la ideología del didactismo, los centros cívicos, la condescendencia disfrazada de empatía que en lugar de ayudar al individuo lo sustituye, etc. Sabemos contra qué se ha escrito. Pero, ¿para quién o para qué? 
C.M.: Hay algo que no podemos soslayar y son las condiciones materiales de la creación y el destino previo de esa obra. Me parece que la pregunta "para" quiere ser muy trascendental, pero en este caso la trascendencia baja al suelo, porque había un "para" inmediato y material: "tiene que gustar a las editoras". Entonces, quizá podemos responder de una manera muy llana y simple, pero que tiene mucha cola: está escrita para ser publicada. Eso significa una carrera de obstáculos: con todo esos "contras", a pesar de ellos, se publica. O esos "contras" tienen que aprender a saltar y a correr y a hacer un triatlón.

A parte, si he conseguido ser destructiva ya me pongo una corona de laureles. El otro día le ofrecieron a mi marido currar con una de esas bolas gigantescas destructoras de edificios y yo pensaba: "¡tío! ¡Ese curro lo quiero yo para mí! ¡Yo quiero saber manejar esa bola gigantesca!". Pareciera que habría que ser algo más que destructiva siempre: como el objetivo del sistema no es sino reproducirse, siempre tiene que haber al lado de la crítica una posición constructiva para su perpetuación. No creo que una novela tenga que aplicarse esas mismas exigencias, ni siquiera que nosotras como agentes críticas tengamos que imponernos el ser constructivas en todo caso. Además, la destrucción se va construyendo poco a poco en la novela: la estipulación del discurso deconstructor y destructivo es un currazo también.

Pero creo que en Lectura fácil sí que hay un lugar de celebración que yo no configuro dentro de mí como "a la contra de", de manera deconstructiva, sino como construcción paulatina de otra cosa: el deseo sexual en Marga... Ser cuidadosa en describir cómo vive ella la sexualidad y qué significaría sentirse libre sexualmente, al punto que, cuando le dicen que quizá la esterilizan, ella responde: "ah, pues mira, así puedo follar más alegremente". A ese punto.

A.P.F.: Retomando aquellas "policías de nosotras mismas" que mencionabas, te propongo que vayamos a otra de las "policías" que opera en el sistema académicoliterario. Una de las manifestaciones del poder patriarcal que nos hermana en este marco son las múltiples formas de desautorización y estereotipación del lugar de enunciación en el que la crítica y los discursos sobre las escritoras mujeres nos sitúan. En un texto sobre Teresa de Jesús que pones "como ejemplo de crítica machista y de concepción ultraconservadora de la literatura" (Morales 2020a: 33), Javier Marías afirma que "los logros expresivos de la Santa no pertenecen al dominio de los valores literarios indisputablemente tales"; que su "alma inmensa [...] no puede contemplarse con los frívolos anteojos de la literatura" (1993). He aquí otro crítico que se niega a "discutir literariamente" sobre la obra de una autora y con esa autora. ¿A qué crees que sirve este arbitraje de "los valores literarios indisputablemente tales"? ¿Contra qué se blinda? ¿Y con qué otras formas de crítica misógina te has encontrado en la recepción de tu obra?

C.M.: Santa Teresa escupe sobre Javier Marías y Javier Marías se da cuenta y lanza ese vuelo gallináceo... ¿En qué estaba pensando? Quizá estaba tan embebido ideológicamente de su poder y de la posición que ocupaba en el sistema literario ya en los 90, que llegaba a pensar que ¡no podía hablar literariamente con Santa 
Teresa de Jesús! O quizás hay una ceguera genuina ahí y se levantó ese día con el pie contrario... Esto me lo pregunto muchas veces: cuando critican de esa manera, ¿están en serio o en broma? ¿O que nos hagan preguntarnos si va en serio o en broma es precisamente una estrategia más de la arbitrariedad de su poder, como están haciendo los gobiernos con nosotros ahora? Porque esto es una faceta más del poder: su posibilidad de inverosimilitud. Lo dice muy bien Marta Sanz cuando habla de la tiranía de la verosimilitud en el universo literario.

Recientemente, Ignacio Echevarría hizo una crítica que me llamó particularmente la atención porque significaba muchas cosas a la vez. Dedicó su columna del jueves en El Cultural a criticar, ya no la obra, sino el prólogo de Introducción a Teresa de Jesús (2020) -recientemente rebautizado como últimas tardes con Teresa de Jesús (2020)-..$^{2}$ Ello me parece que es darle la entidad que merece al prólogo, donde yo exponía cuáles habían sido las condiciones de creación de esta novela mía y en el que era muy crítica con las dinámicas que adoptan las editoriales hacia escritores y escritoras jóvenes: las miserias que vivía yo entonces, en 2015. Pero la conclusión de Echevarría fue que yo no había entendido nada, que no entiendo cómo va el mundo editorial. De nuevo, eso es no reconocer el disenso, y es una forma de desprecio, claro está. Por un lado, se refería a mí como si fuera una chiquilla que no llevara no sé cuántos libros publicados de manera individual y no sé cuántos de manera colectiva. Y yo ya había ganado el Premio Herralde y el Premio Nacional de Narrativa. Eso también genera mucho estupor: cuando una no ha sido llamada por el poder a ocupar un lugar de legitimidad, da igual los premios que gane, que no se la va a tratar con esa legitimidad. Y la batalla no acaba. Por otro lado, esa columna me pareció la manera que tenía un crítico muy tradicional de lanzar un capote a la obra, que no dejaba de ser una reedición y que no iba a tener una gran difusión ni promoción. Y, aunque no lo he hablado con él personalmente (podría hacerlo), entreví al mismo tiempo que ese capote se lanzaba queriendo incidir en la propia posición de poder. No se da el brazo a torcer en ningún momento. En fin, no sé si llamar misóginas a este tipo de críticas, pero, desde luego, responden a inercias o a cegueras de aquellos que no han necesitado quitarse nunca los anteojos.

A.P.F.: Esta constante batalla por la legitimidad por parte de las que no hemos sido llamadas a ocupar un lugar de legitimidad me recuerda a un fragmento de Introducción a Santa Teresa de Jesús, cuando Teresa le propone a su compañera Juana dejar de ser "invitadas" para ser "anfitrionas" (Morales 2020b: 107). ¿Cómo podemos llevar a cabo esa reapropiación de espacios en los que parece que seguimos siendo percibidas como apenas "invitadas"?

C.M.: Me doy cuenta de que efectivamente hay lugares en que no soy esperada y ocurren estas reacciones de las que hablábamos, como la de Echevarría. Pero también debo decir que nunca he sentido que tuviera que "reapropiarme" de los

\footnotetext{
2 Ambos volúmenes recogen el texto publicado inicialmente en Lumen bajo el título de Malas palabras (2015), acompañado por el prólogo al que se refiere la autora: "Nota a la edición: ¡Ja ja ja ja!" (2020b: 29-39).
} 
lugares de foco o de voz que el poder me da: nunca he ido con el complejo de que no fueran míos ya. El 8 de marzo de 2019 fui invitada a El Corte Inglés para hablar con Rosa Montero sobre Lectura fácil: si me invitan a El Corte Inglés, es mi espacio, esa hora es mía. Estoy entrando legalmente a este lugar, no me estoy colando, y nadie me ha hecho firmar un documento sobre qué debo y qué no debo decir. Esto es muy importante. En ese caso fue divertido porque, siendo que ese lugar era mío, era un lugar muy incómodo. Entonces, ahí sí que fui preparada con una serie de reflexiones sobre robar libros en El Corte Inglés. Y fue, no sé si una victoria, pero sí un consuelo a nivel interno que me hacía al menos no tener pesadillas por estar allí. Esto lo he ido descubriendo: que si alguien me da una libertad, me la tomo, y que se puede morder la mano que te da de comer. Además, la experiencia me dice que morder la mano que te da de comer no es tan peligroso. En primer lugar, porque no somos tan dañinas $y$, en segundo lugar, porque cooptan tu imagen y puede que el discurso quede en un segundo plano: un montón de cosas que escapan a tu control. No obstante, insisto en que el lugar donde soy invitada no me lo tengo que reapropiar. Me han dicho: "Bienvenida, pase usted".

Lo mismo me ocurre en lugares de mucho prestigio institucional, donde cierta izquierda pretende que yo reble ante el mismísimo Premio Nacional. ¿Por qué debería yo renunciar a algo que es tan legítimamente mío? Incluso entre mujeres, entre nosotras mismas como policías o críticas con nosotras mismas, a menudo existe el complejo de negar la evidencia: ¿por qué ha sido premiada la obra? Por los tiempos que corren, el feminismo, el boom del 8M, porque es una mujer, por la destrucción del "autor macho" que enuncia tan bien Luna Miguel... Entonces, ni nosotras mismas decimos: "le han dado el premio porque ha escrito una novela de puta madre". Eso no quita que luego seamos superanalíticas y digamos: "jah! Esa novela la pudo escribir Marta Sanz hace diez años y nunca le habían dado el Premio Nacional". Efectivamente, pero que eso no nos haga pedir perdón por los logros: he escrito una novela que ha merecido un premio y no me estoy apropiando de nada. Percibo un gran pudor en nuestra sociedad tanto en el pedir como en el aceptar y un gran sentimiento judeocristiano de deuda y de culpa en todo caso, que no encuentro en Latinoamérica (conozco un poco Colombia por razones familiares). Y la consecuencia primera y más terrorífica es que tenemos menos disposición a la celebración y a la fiesta.

A.P.F.: ¿No se espera que en El Corte Inglés hables sobre robar libros en El Corte Inglés? Es decir, ¿no se acaba reasimilando y neutralizando tu "apropiación" de esos espacios?

C.M.: En este caso concreto no lo sé, pero si pensáramos así de cualquier acto de contestación restaríamos valor a cualquier acto de contestación: es la mejor excusa para la falta de acción. Pensar que las consecuencias de cada acto contrario al statu quo siempre van a beneficiar al statu quo me parece que es el discurso enarbolado por el statu quo; es la manera que tienen los detentadores del poder hegemónico de denostar cualquier tipo de subversión.

M.C.S.: Me he quedado pensando en esa imagen "cooptada", al margen de cómo y en qué grado una haya contribuido o no a crearla, y quería preguntarte por tu pos- 
tura de autora. Me gusta mucho la imagen de la "aguafiestas feminista", de Sarah Ahmed (2019), o -sin querer descontextualizarla porque proviene de los feminismos negros- la de la "angry black woman": aquella que llega a destruir la paz de una cena de navidad, a desvelar los entresijos del sistema literario, asistencialista, capitalista, etc. Con su rabia, con su indignación. ¿Reconoces esta filiación en tu postura, ya sea porque la hayas generado tú o porque así haya sido leída? Esta imagen de la feminista que aboga por la destrucción, con esa "bola gigantesca" a la que te referías, ¿crees que, en el campo literario actual, sirve como una especie de contrapunto a la de esa autora cuya política feminista es la visibilización y la inclusión de más y más escritoras? Estoy pensando otra vez en Los Combatientes, en esa mesa "feminizante feminizada fémina".

C.M.: Esta imagen de "la aguafiestas" es guapísima. Me recuerda a unas charlas online que tuve hace unos días en la Feria del Libro de Buenos Aires, con Ariana Harwicz y Juan José Becerra. Él hablaba del escritor en sociedad como aquel con quien no te quieres encontrar en una fiesta, con quien mides tus palabras, a quien temes; alguien difícilmente bienvenido. Lo decía de manera brillantísima y nos convenció a Ariana y a mí. Yo me quedo con lo de ser temible y destripadora, pero con aguafiestas no. Como seguimos manejando el binomio que distingue lo intelectual y lo festivo, lo físico y el cuerpo de la mente, parece que la gente que es absolutamente crítica no quiere relacionarse con sus iguales a través de lo festivo. Yo haría fiestas todo el rato. Como me dedico también a la danza, a veces digo que me la pasaría bailando en vez de escribiendo.

Sobre la cuestión de los contrapuntos, también entra dentro de los binomios, ¿no? No tengo una idea clara de esa otra escritora abrazadora, inclusiva, pero estoy convencida de que esos lugares son lugares pre-creados (posiblemente creados también por algunas de nosotras) que acaban convirtiéndose en lugares perfectamente delimitados por el mundo editorial: acaban siendo nichos de mercado donde una autora puede decidir encajar. Creo que una vez ya pueden ser articulados y enunciados ("la autora inclusiva que quiere visibilizar", etc.), en cuanto podemos enumerarlos, significa que ya son casillas prefabricadas y que, como tales, tenemos en nuestra mano transformarlas u ocuparlas y reventarlas o sacarles beneficio.

A.P.F.: Me atrevo a aventurar que quizá se está creando otra "casilla" que justamente rompe con la jerarquía entre formas "intelectuales" de intervenir en la "realidad" y formas menos prestigiadas. Y quizá esa otra "casilla" tendría que ver con lo que afirmas en tu texto sobre María Galindo, donde hablas de la escritura como "algo ejecutable en los cuerpos", de escribir "con las mismas motivaciones con las que se roba un banco", "se okupa una finca o un cuartel" o "se les pega una paliza a unos fascistas" (Morales 2018a: 48). En esta escritura y en esta desjerarquización de la escritura frente a otras prácticas, ¿podríamos encontrar una vía para pensar una nueva forma de relación de la autora y el espacio común?

C.M.: Ojalá fuera así, Aina. Estás describiendo un panorama maravilloso donde no hay jerarquía entre la quema del contenedor y la escritura del poema. Me quiero 
preguntar a mí misma si yo hago esfuerzos por generar ese paraíso cuando escribo. Podría ser paradójico, porque si yo genero ese paraíso lo hago de manera visible, porque es una publicación, una publicación de Anagrama. La quema de contenedores, que es secreta, que es en colectivo o que dura un momento, no maneja los mismos términos de visibilización; no interviene la noción de autoría de la misma manera. Pero, como defensora de la invisibilización, ya me va bien que haya espacios invisibles y puntos ciegos. La escritura, y la escritura publicada, va a ser visible siempre y, como arma, estas son sus posibilidades: tiene a su favor la visibilidad y tiene en su contra la visibilidad. Me la quiero tomar como una herramienta más, como un arma más. Qué duda cabe. Pero no como una llamada a la acción donde sea la escritura la que configure el tipo de acción, donde sea preeminente en la toma de decisión.

Mi experiencia es que a mí no se me da más voz en los espacios colectivos que frecuento, y que frecuentaba antes de escribir Lectura fácil, por haber escrito una novela. Hay incluso la posición contraria a escribir. "¿De qué trabajas?": "soy escritora". Lo contrario a la líder obrera. No soy una curranta que está en una cafetería; no soy una curranta que cuida a personas mayores; no soy una trabajadora sexual -esto lo podríamos debatir-o, al menos, no una trabajadora sexual que se define como tal. Entonces, también me he encontrado, dentro de los espacios liberados, con discursos de desprestigio de la tarea de la escritura como una tarea política de primer orden. Se sigue asumiendo como una tarea eminentemente burguesa. Cuando gané el Premio Herralde hicimos varias charlas donde se hablaba de arte y acción que nos permitieron poner el foco en el poco valor que le damos al arte en nuestros espacios liberados. Ese lugar de debate donde mis iguales no conciben la escritura como un espacio prestigiado, sino todo lo contrario, me interesa mucho más. O sea, me interesa más defender que mi trabajo en la acción es valioso rodeada de los compañeros que no se creen que, efectivamente, sentada en una silla y tecleando, se pueda estar haciendo algo, que tener que justificar que la escritura es transformadora delante de El Corte Inglés.

M.C.S.: ¿Podrías desarrollar lo que has apuntado sobre que se te podría considerar, o no, una trabajadora sexual?

C.M.: Es la tercera o cuarta vez que cito a María Galindo, mi Santa: Santa María Galindo. Ella tiene un ensayo, Ninguna mujer nace para puta (2007), cuyo título podría sonar abolicionista. Nada más lejos: es abolicionista del trabajo. Entiende que nuestro ingreso al trabajo remunerado, con la modernidad de la Revolución Industrial, tiene siempre un vector sexual. O sea, equipara a la esposa y a la puta. Creo que, en mi condición de mujer remunerada en un sistema patriarcal, muy difícilmente se va a dejar de lado la seducción, por ejemplo, como vertebradora de la relación laboral; no se va a dejar de entender el juego de roles de género como imprescindible para la supervivencia en el puesto de trabajo de que se trate. Esto puede pasar por gestos, por la obligatoriedad que una siente de sonreír o ser amable, y estas tareas apelan directamente a la concepción de nosotras como 
proporcionadoras de placer sexual. Si no como proporcionadoras de placer sexual inmediato, sí de un placer sexual simbólico que hace que nuestro patrón (sea un patrón o una patrona, pero con esa raíz en el pater) esté satisfecho y sereno en la relación de dominio. Entiendo perfectamente que, desde una perspectiva sindical o colectiva, "trabajadora sexual" necesite definirse por cierto numerus clausus, por ciertas características. Pero considero que eso no puede dejar de lado una reflexión más profunda. Es lo mismo que comentaba antes sobre el salario: ¿qué viene a pagar? ¿Viene a pagar el artículo que escribo, las horas de clase o la charla que doy, el manuscrito que te entrego? ¿Seguro que viene a pagar eso? Para mí claramente viene a pagar otra cosa: un sostenimiento de relaciones de poder que, siempre que interviene una mujer como parte asalariada, tienen un elemento sexual y en las que se da placer sexual.

A.P.F.: Una de las formas más evidentes de la alianza entre activismo y literatura la encontramos en el protagonismo de los transfeminismos y de los activismos LGTBIQ en el discurso público y en la producción ensayística y literaria de muches escritores actuales, en un movimiento transnacional y transhispánico que ejemplifican los Tsunami mexicano y español (Jáuregui 2018 y Sanz 2019, respectivamente). Si a ello añadimos la crítica a la racialización y al postcolonialismo articulada desde los feminismos latinoamericanos, parece que en este tsunami se está fraguando otro espacio no previsto para un simposio como este. Un espacio en el que ya no se trata simplemente de "autorías femeninas" o de "literatura escrita por mujeres", sino de una guerrilla conformada por todes aquelles excluides de la figura del Autor. En este sentido, ¿lograremos "matar al autor" masculino, cisgénero, heterosexual, blanco, capacitado y burgués, etc.?

C.M.: En verdad, lo que me estás preguntando es si tengo esperanzas o no. Ya que estábamos hablando de casillas, hay que decir que "el autor macho, cisgénero, etc." también lo es y que, en tanto que casilla, bien puede ser deconstruida, se puede escupir sobre ella, y creo que haríamos bien en no percibirla como totémica y todopoderosa. Innegablemente, ese poder existe, no nos lo inventamos, pero cuando lo estamos enunciando así nos estamos dando a nosotras mismas la libertad de nombrarlo con características que quizá en otro momento estaban invisibilizadas, ciegas, que son desagradables, y eso ya es un gran poder. Creo que, del mismo modo que la hemos construido y nos sirve analíticamente, bien podemos empezar a desplazarla, colocarla en lugares inesperados, igual que Galindo habla de las "alianzas inesperadas".

Antes de que saliera Lectura fácil, me invitaron a dar una charla en Sevilla con Juan Manuel de Prada. Yo había escrito Terroristas modernos (2017), una novela situada en el siglo xIx que es muy crítica con el liberalismo recién acuñado en España después de la Guerra de Independencia. Y Juan Manuel de Prada es un autodeclarado antiliberal-también se autodeclara una persona muy católica. La alianza ahí fue inesperada, pero muy gustosa: nos poníamos a repartir candela contra el liberalismo decimonónico, y no había quien nos parara. Alguien podría decir que, hablando del liberalismo decimonónico, todos estamos de 
acuerdo, pero que si nos ponemos a hablar de teoría queer... Bueno, pero puedo hablar con Juan Manuel de Prada de liberalismo decimonónico, de crítica a la modernidad y al progreso. ¿Dónde te encuentras con alguien que te hable contra el progreso en el star system literario? ¿Con alguien que te hable en contra de la libertad de expresión como hecho creado? De pronto, hablar ya no es hablar y escribir ya no es escribir: es que está amparado por un derecho; la engañifa liberal es total. Cuando voy sola y digo que estoy en contra de la libertad de expresión, me dicen que el anarquismo y la ultraderecha se tocan, etc. Con Juan Manuel de Prada, que es un señor muy respetado, nadie me decía a mí nada. La "alianza inesperada".

Creo que hay que coger la casilla del autor macho cisgénero y tomar lo valioso que puede haber en ella. Y de valioso en ella puede haber cosas materiales y físicas como que pueda darse el encuentro. Yo no tengo miedo al macho. A muchos de ellos incluso me los quiero follar. Vengan a mí, adelante. También me parece que haríamos muy bien en reconocer, desde un lugar autocrítico, lo que hay en nosotras de machas, los deseos de ocupar o emular posiciones y privilegios y de ejecutarlos de la misma manera.

\section{OBRAS CITADAS}

Ahmed, Sarah (2019). La promesa de la felicidad. Una crítica cultural al imperativo de la alegría. Buenos Aires: Caja Negra.

Echevarría, Ignacio (2020). "Malas palabras", El Cultural. <https://elcultural.com/malas-palabras-2> (10 de junio de 2021).

Galindo, María (2013). Ninguna mujer nace para puta. Madrid: Traficantes de Sueños [2007]. Jáuregui, Gabriela (ed.) (2018). Tsunami. México: Sexto Piso.

Marías, Javier (1993). "El libro de la Vida. Éxito y fracaso de Santa Teresa", in Breve biblioteca de autores españoles, ed. Francisco Rico. Barcelona: Seix Barral, 123-125.

Morales, Cristina (2020a). Los combatientes [2013]. Barcelona: Anagrama.

Morales, Cristina (2020b). Últimas tardes con Teresa de Jesús. Barcelona: Anagrama.

Morales, Cristina (2018a). "María Galindo. La filósofa del placer", Letras libres, 203: 46-50. [Publicado bajo el título "María Galindo. Todas tenemos cara de puta" en <https:// www.letraslibres.com/mexico/revista/maria-galindo-todas-tenemos-cara-puta> (10 de junio de 2021)]

Morales, Cristina (2018b). Lectura fácil. Barcelona: Anagrama.

Morales, Cristina (2017). Terroristas modernos. Barcelona: Candaya.

Pozuelo Yvancos, José María (2019). "El sermón anarquista de Cristina Morales", ABC. Cultural. <https://www.abc.es/cultura/cultural/abci-sermon-anarquista-cristina-morales-201911060116_noticia.html" (1 de septiembre de 2021).

Sanz, Marta (ed.) (2019). Tsunami. Miradas feministas. Madrid: Sexto Piso.

Suau, Nadal (2018). "Lectura fácil", El Cultural. <https://elcultural.com/lectura-facil-2> (1 de septiembre de 2021). 